\title{
Can News Be a Major Source Of Aggregate Fluctuations? A BAYESIAN DSGE APPROACH
}

\author{
by
}

Ippei Fujiwara, Yasuo Hirose, and Mototsugu Shintani

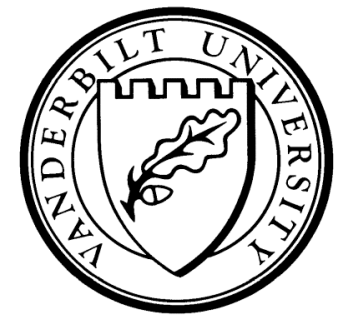

Working Paper No. 09-W21

December 2009

\section{DEPARTMENT OF ECONOMICS \\ VANDERBILT UNIVERSITY \\ NASHVILLE, TN 37235}

www.vanderbilt.edu/econ 


\title{
Can News Be a Major Source of Aggregate Fluctuations? A Bayesian DSGE Approach*
}

\author{
Ippei Fujiwara $^{\dagger} \quad$ Yasuo Hirose $^{\ddagger} \quad$ Mototsugu Shintani ${ }^{\S}$
}

First draft: April 2008

This version: December 2009

\begin{abstract}
We examine whether the news shocks, as explored in Beaudry and Portier (2004), can be a major source of aggregate fluctuations. For this purpose, we extend a standard dynamic stochastic general equilibrium model of Christiano, Eichenbaum, and Evans (2005) and Smets and Wouters $(2003,2007)$ by allowing news shocks on the total factor productivity, and estimate the model using Bayesian methods. Estimation results on the U.S. and Japanese economies suggest that (1) news shocks play a relatively more important role in the U.S. than in Japan; (2) a news shock with a longer forecast horizon has larger effects on nominal variables; and (3) the overall effect of the total factor productivity on hours worked becomes ambiguous in the presence of news shocks.
\end{abstract}

JEL Classification: E30; E40; E50

Keywords: $\quad$ Bayesian Estimation; Business Cycles; News

*We thank Larry Christiano, Mario Crucini, Eric Leeper, Kevin Huang, Masaru Inaba, Giorgio Primiceri, Frank Smets and the seminar and conference participants at Tohoku University, Vanderbilt University and the FRB Philadelphia / NBER Workshop on Methods and Applications for DSGE Models, the 2009 Far East and South Asia Meetings of the Econometric Society, and the 10th CIRJE-TCER Macroeconomics Conference for helpful comments and discussion. We also thank Tomohiro Sugo and Kozo Ueda for providing us with the data. Views expressed in this paper are those of the authors and do not necessarily reflect the official views of the Bank of Japan.

${ }^{\dagger}$ Financial Markets Department, Bank of Japan. E-mail: ippei.fujiwara@boj.or.jp

${ }^{\ddagger}$ Monetary Affairs Department, Bank of Japan. E-mail: yasuo.hirose@boj.or.jp

${ }^{\S}$ Department of Economics, Vanderbilt University. E-mail: mototsugu.shintani@vanderbilt.edu 


\section{Introduction}

Macroeconomists have long realized that changes in expectations about the future can be a major source of economic fluctuations. This tradition can be traced back to Pigou (1926), who emphasized the possibility that capital accumulation, caused by optimistic expectations of future demand increase, may result in recessions when the expectations are not met. ${ }^{1}$ This idea of expectation-driven cycles, sometimes referred to as "Pigou cycles," has recently been reformulated in the framework of modern equilibrium business cycle models. ${ }^{2}$ Theoretical works that successfully yielded procyclical labor, investment, and consumption in the presence of news shocks include Beaudry and Portier (2004), Beaudry, Collard, and Portier (2006), Denhaan and Kaltenbrunner (2007), Fujiwara (2007), Kobayashi, Nakajima, and Inaba (2007), Christiano, Ilut, Motto, and Rostagno (2008) and Jaimovich and Rebelo (2009). In contrast to growing interest in the theoretical analysis, the empirical evidence on the importance of news shocks in business cycles is quite limited. Some exceptions are Beaudry and Portier (2006) for the United States and Beaudry and Portier (2005) for Japan. They identified the news shocks by estimating a structural vector autoregression (VAR) model with an assumption that the news shock has an impact on both the stock price and total factor productivity (TFP) in the long run but not on the latter in the short run.

In this paper, we empirically examine the role of news shocks in explaining business cycles through an estimated dynamic stochastic general equilibrium (DSGE) model. In particular, we introduce both anticipated and unanticipated components in the TFP and evaluate the relative contribution of the two components to aggregate fluctuations by estimating a standard New Keynesian DSGE model based on the U.S. and Japanese data. Although our analysis is similar to Beaudry and Portier $(2005,2006)$ in spirit, it has several advantages over their VAR approach. First, we directly estimate a fully specified DSGE model, and thus interpretation of our results, such as variance decompositions and impulse responses, is straightforward. ${ }^{3}$ Second, since our

\footnotetext{
${ }^{1}$ Pigou (1926) states that "while recognizing that the varying expectations of business men may themselves be in part a psychological reflex of good and bad harvests - while not, indeed, for the present inquiring how these varying expectations themselves come about - we conclude definitely that they, and not anything else, constitute the immediate cause and direct causes or antecedents of industrial fluctuations."

${ }^{2}$ For example, the term of "Pigou cycles" has been used by Beaudry and Portier (2004).

${ }^{3}$ Recent works by Schmitt-Grohé and Uribe (2008), Khan and Tsoukalas (2009) and
} 
model allows the presence of multiple news shocks with different forecast horizons, the role of horizons in news shocks can be systematically examined.

As pointed out by Barro and King (1984), generating the expectation-driven cycles in equilibrium models has been a difficult task, since "with a simple one-capital-good technology, no combination of income effects and shifts to the perceived profitability of investment will yield positive comovements of output, employment, investment, and consumption (p. 818)." Only recently have the Pigou cycles been successfully described by balancing the tension between the wealth effect and the substitution effect stemming from the expectation of changes in future productivity. ${ }^{4}$ The pioneering work by Beaudry and Portier (2004) has shown that the introduction of the multi-sectoral adjustment cost intensifies the complementarity between consumption and investment, which leads to the comovement of consumption, labor, and investment. Later, Christiano, Ilut, Motto, and Rostagno (2008) pointed out that the Pigou cycles could also be produced in the de facto standard macroeconomic model of Christiano, Eichenbaum and Evans (2005) (hereafter CEE), namely, a DSGE model that incorporates the investment growth adjustment cost, habit formation in consumption, sticky prices and wages, and the inflation-targeting monetary policy.

To examine the role of news shocks, we follow Smets and Wouters $(2003,2007)$ and estimate a CEE-type DSGE model using the Bayesian procedure. We choose to focus on the CEE-type model in our analysis for various reasons. First, this model is one of the most commonly used sticky price models among practitioners because it can account for many important characteristics of macroeconomic data, such as the inflation inertia and output persistence. ${ }^{5}$ Second, the model contains all essential features, according to Christiano, Ilut, Motto, and Rostagno (2008), in producing Pigou cycles. Third, Smets and Wouters $(2003,2007)$ have already established that the CEE-type model estimated by Bayesian methods fits well with the U.S. and Euro data, and that the out-of-sample forecasting performance of the estimated model is comparable to that of

\footnotetext{
Milani and Treadwell (2009) also employed a Bayesian DSGE method similar to ours.

${ }^{4}$ With a positive news shock in TFP, for example, the wealth effect reduces labor and investment, while the substitution effect reduces consumption. A Dynare toolkit created by Fujiwara and Kang (2006) can be used to compute the impulse responses to news shocks under many different scenarios.

${ }^{5}$ In fact, many models developed by central banks can be viewed as variations of CEE. For example, see Laxton and Pesenti (2003), Erceg, Guerrieri, and Gust (2006), Adolfson, Laseen, Linde, and Villani (2007), and Sugo and Ueda (2008).
} 
a standard Bayesian VAR model.

Our estimation results from U.S. quarterly data show that, while the anticipated and unanticipated shocks in the TFP together can account for only 20 to 30 percent of the aggregate fluctuations at most, the contribution of the news shocks in TFP is often larger than that of the unanticipated TFP shocks. When the forecast horizon of the news shock becomes longer, the effects of the news shocks on nominal variables become larger. Furthermore, the overall effect of the TFP innovations on hours worked, which has been one of the key issues in the recent business cycle literature, becomes ambiguous when both news and contemporaneous shocks occur simultaneously. In contrast to the U.S. case, estimates from Japanese quarterly data show that the unanticipated TFP shocks are the dominant driver of aggregate output fluctuation, and the contributions of the anticipated shocks in TFP are much smaller than those of the unanticipated shocks.

The remainder of this paper is structured as follows. In Section 2, the concepts of news shocks are first introduced, followed by the description of the log-linearized model. In Section 3, the estimation strategy is explained. Estimation results using U.S. data are demonstrated in Section 4. In Section 5, discussions, including a comparison with Japanese results, are provided. Concluding remarks are made in Section 6. The details of the theoretical model are provided in an appendix.

\section{The Model}

\subsection{News Shocks in Productivity}

As in Beaudry and Portier (2004), we consider the case where agents can observe signals that contain information on future technological innovations. Other than allowing for such an information structure, both our production function and innovation process are fairly standard. In what follows, all the variables are expressed in terms of log deviation from the steady-state values. Let $y_{t}, k_{t}^{s}, l_{t}$, and $z_{t}$ be the output, the current capital services in production, the hours worked, and the TFP around the deterministic linear trend, respectively. Our (log-linearized) 
aggregate production function is given by

$$
y_{t}=\phi_{p}\left[\alpha k_{t}^{s}+(1-\alpha) l_{t}+z_{t}\right]
$$

where $\phi_{p}$ denotes one plus the share of the fixed costs in production and $\alpha$ represents the capital share. The detrended TFP $z_{t}$ is assumed to follow an AR (1) process:

$$
z_{t}=\rho_{z} z_{t-1}+\varepsilon_{t}^{z}, \quad \varepsilon_{t}^{z} \sim \text { i.i.d. } \quad N\left(0, \sigma_{z}^{2}\right)
$$

where $\varepsilon_{t}^{z}$ is a technological innovation in productivity. To introduce the information structure, it is convenient to rewrite $\varepsilon_{t}^{z}$ as a summation of the unanticipated component, $\nu_{0, t}$, and the anticipated component, $\nu_{t}^{*}$. At the beginning of period $t, \nu_{0, t}$ is not known but $\nu_{t}^{*}$ is known to agents. To allow for the variation in the timing of the arrival of the news, we further decompose the latter component $\nu_{t}^{*}$ into a summation of news shocks, or $\sum_{h=1}^{H} \nu_{h, t-h}$, where $\nu_{h, t-h}$ is news of the $h$-period-ahead technological innovation learned at period $t-h$, where $0<h \leq H$. For identification, we assume

$$
\nu_{h, t} \sim \text { i.i.d. } N\left(0, \sigma_{z h}^{2}\right), \quad \text { for } h=0,1, \ldots, H \text {. }
$$

This assumption implies zero correlation between the news and contemporaneous shocks as well as zero cross-correlation among news shocks of different horizons. The variance of $\varepsilon_{t}^{z}$ can be simply computed as $\sigma_{z}^{2}=\sum_{h=0}^{H} \sigma_{z h}^{2}$. As an example, let us consider the case when the agents can obtain news about future technology up to four periods ahead $(H=4)$. The technology process can then be written as

$$
\begin{aligned}
z_{t} & =\rho_{z} z_{t-1}+\nu_{0, t}+\nu_{t}^{*} \\
& =\rho_{z} z_{t-1}+\nu_{0, t}+\nu_{1, t-1}+\nu_{2, t-2}+\nu_{3, t-3}+\nu_{4, t-4} .
\end{aligned}
$$

In this case, at the period $t$, agents form rational expectations on the future productivity $z_{t+h}$, $h>0$, using the information set $\left\{z_{t}, \nu_{1, t}, \ldots, \nu_{4, t}, \nu_{1, t-1}, \ldots, \nu_{4, t-1}, \ldots\right\}$. To understand this information updating structure, it is convenient to rewrite the above equation in the canonical form 
as

$$
\left(\begin{array}{c}
z_{t} \\
\nu_{1, t} \\
\nu_{2, t} \\
\nu_{2, t-1} \\
\nu_{3, t} \\
\nu_{3, t-1} \\
\nu_{3, t-2} \\
\nu_{4, t} \\
\nu_{4, t-1} \\
\nu_{4, t-2} \\
\nu_{4, t-3}
\end{array}\right)=\left(\begin{array}{ccccccccccc}
\rho_{z} & 1 & 0 & 1 & 0 & 0 & 1 & 0 & 0 & 0 & 1 \\
0 & 0 & 0 & 0 & 0 & 0 & 0 & 0 & 0 & 0 & 0 \\
0 & 0 & 0 & 0 & 0 & 0 & 0 & 0 & 0 & 0 & 0 \\
0 & 0 & 1 & 0 & 0 & 0 & 0 & 0 & 0 & 0 & 0 \\
0 & 0 & 0 & 0 & 0 & 0 & 0 & 0 & 0 & 0 & 0 \\
0 & 0 & 0 & 0 & 1 & 0 & 0 & 0 & 0 & 0 & 0 \\
0 & 0 & 0 & 0 & 0 & 1 & 0 & 0 & 0 & 0 & 0 \\
0 & 0 & 0 & 0 & 0 & 0 & 0 & 0 & 0 & 0 & 0 \\
0 & 0 & 0 & 0 & 0 & 0 & 0 & 1 & 0 & 0 & 0 \\
0 & 0 & 0 & 0 & 0 & 0 & 0 & 0 & 1 & 0 & 0 \\
0 & 0 & 0 & 0 & 0 & 0 & 0 & 0 & 0 & 1 & 0
\end{array}\right)\left(\begin{array}{c}
z_{t-1} \\
\nu_{1, t-1} \\
\nu_{2, t-1} \\
\nu_{2, t-2} \\
\nu_{3, t-1} \\
\nu_{3, t-2} \\
\nu_{3, t-3} \\
\nu_{4, t-1} \\
\nu_{4, t-2} \\
\nu_{4, t-3} \\
\nu_{4, t-4}
\end{array}\right)+\left(\begin{array}{c}
\nu_{0, t} \\
\nu_{1, t} \\
\nu_{2, t} \\
0 \\
\nu_{3, t} \\
0 \\
0 \\
\nu_{4, t} \\
0 \\
0 \\
0
\end{array}\right)
$$

or $\mathbf{s}_{t}=A \mathbf{s}_{t-1}+\varepsilon_{t}$, where $\mathbf{s}_{t}=\left(z_{t}, \nu_{1, t}, \nu_{2, t}, \nu_{2, t-1}, \ldots, \nu_{4, t-3}\right)^{\prime}$ and $\varepsilon_{t}=\left(\nu_{0, t}, \nu_{1, t}\right.$, $\left.\nu_{2, t}, 0, \nu_{3, t}, \ldots, 0\right)^{\prime}$. Note that $\mathrm{E}_{t} z_{t+h}$, the $h$-period-ahead forecast of $z_{t}$ at period $t$, can be easily obtained as an element in $\mathrm{E}_{t} \mathbf{s}_{t+h}$ using $\mathbf{s}_{t+h}=A^{h} \mathbf{s}_{t+h-1}+\ldots+\varepsilon_{t+h}$. For example, the news $\nu_{4, t}$, the 4-period-ahead technological progress learned at period $t$, will have no effect on $z_{t}, \mathrm{E}_{t} z_{t+1}$, $\mathrm{E}_{t} z_{t+2}$, and $\mathrm{E}_{t} z_{t+3}$. However, $\nu_{4, t}$ will have an impact on $\mathrm{E}_{t} z_{t+4}\left(\right.$ and $\mathrm{E}_{t} z_{t+h}$ for $\left.h>4\right)$, since the first element of $\mathrm{E}_{t} \mathbf{s}_{t+4}$ is given by

$$
\begin{aligned}
\mathrm{E}_{t} z_{t+4}= & \rho_{z}^{4} z_{t-1}+\rho_{z}^{3}\left(\nu_{1, t}+\nu_{2, t-1}+\nu_{3, t-2}+\nu_{4, t-3}\right) \\
& +\rho_{z}^{2}\left(\nu_{2, t}+\nu_{3, t-1}+\nu_{4, t-2}\right)+\rho_{z}\left(\nu_{3, t}+\nu_{4, t-1}\right)+\nu_{4, t} .
\end{aligned}
$$

In the empirical section, we search for the news horizon $H$ based on the data.

\subsection{Other Shocks in the Linearized System}

The remaining part of the model is a slightly simplified version of the CEE-type model used in Smets and Wouters $(2003,2007)$. Here we only show the log-linearized system of equations (see the appendix for the full model). Let $c_{t}, i_{t}, r_{t}^{k}$, and $k_{t}$ be the consumption, the investment, the rental rate of capital, and the physical capital. The current capital services in production $k_{t}^{s}$ are defined as

$$
k_{t}^{s}=k_{t-1}+u_{t}
$$

where $u_{t}$ is the capacity utilization rate, which is given by

$$
u_{t}=\frac{1-\psi}{\psi} r_{t}^{k}
$$


where $\psi$ is a positive function of the elasticity of capacity utilization adjustment cost function normalized to be between zero to unity. The aggregate resource constraint is

$$
y_{t}=\frac{c}{y} c_{t}+\frac{i}{y} i_{t}+\frac{r^{k} k}{y} u_{t}+g_{t}
$$

where $g_{t}$ is the government expenditure shock. The variables without time subscript are steady state values. The consumption Euler equation is expressed as

$$
\begin{aligned}
c_{t}= & \frac{\lambda}{\gamma\left(1+\frac{\lambda}{\gamma}\right)} c_{t-1}+\left[1-\frac{\lambda}{\gamma\left(1+\frac{\lambda}{\gamma}\right)}\right] \mathrm{E}_{t} c_{t+1} \\
& +\frac{\left(\sigma_{c}-1\right)\left(\frac{w l}{C}\right)}{\sigma_{c}\left(1+\frac{\lambda}{\gamma}\right)}\left(l_{t}-\mathrm{E}_{t} l_{t+1}\right) \\
& -\frac{1-\frac{\lambda}{\gamma}}{\sigma_{c}\left(1+\frac{\lambda}{\gamma}\right)}\left(r_{t}-\mathrm{E}_{t} \pi_{t+1}\right)
\end{aligned}
$$

where $r_{t}$ denotes the nominal interest rate, $w_{t}$ is the nominal wage, and $\pi_{t}$ represents the inflation rate, while $\lambda$ is the parameter on the external habit, $\gamma$ is the steady-state growth rate, and $\sigma_{c}$ represents the inverse of the intertemporal elasticity of substitution. The investment Euler equation is given by

$$
i_{t}=\frac{1}{1+\beta \gamma^{1-\sigma_{c}}} i_{t-1}+\left(1-\frac{1}{1+\beta \gamma^{1-\sigma_{c}}}\right) \mathrm{E}_{t} i_{t+1}+\frac{1}{\left(1+\beta \gamma^{1-\sigma_{c}}\right) \gamma^{2} \varphi} q_{t}+v_{t}
$$

where $q_{t}$ is the real value of existing capital and $v_{t}$ is the investment-specific technology process, while $\beta$ denotes the subjective discount factor and $\varphi$ represents the steady-state elasticity of the investment adjustment cost function. The capital Euler equations is now expressed as

$$
\begin{aligned}
q_{t}= & \beta \gamma^{-\sigma_{c}}(1-\delta) \mathrm{E}_{t} q_{t+1}+\left[1-\beta \gamma^{-\sigma_{c}}(1-\delta)\right] \mathrm{E}_{t} r_{t+1}^{k} \\
& -\left(r_{t}-\mathrm{E}_{t} \pi_{t+1}\right)+f_{t}
\end{aligned}
$$

where $f_{t}$ is the external finance premium shock and $\delta$ is the capital depreciation rate. The capital accumulation is given by

$$
k_{t}=\frac{1-\delta}{\gamma} k_{t-1}+\left(1-\frac{1-\delta}{\gamma}\right) i_{t}+\left(1-\frac{1-\delta}{\gamma}\right)\left(1+\beta \gamma^{1-\sigma_{c}}\right) \gamma^{2} \varphi v_{t}
$$

The definition of the price markup $\mu_{t}^{p}$ is

$$
\mu_{t}^{p}=\alpha\left(k_{t}^{s}-l_{t}\right)+z_{t}-w_{t} .
$$


The new Keynesian Phillips curve is given by

$$
\pi_{t}=\frac{\iota_{p}}{1+\beta \gamma^{1-\sigma_{c} \iota} \iota_{p}} \pi_{t-1}+\frac{\beta \gamma^{1-\sigma_{c}}}{1+\beta \gamma^{1-\sigma_{c} \iota_{p}}} \mathrm{E}_{t} \pi_{t+1}-\frac{\left(1-\beta \gamma^{1-\sigma_{c}} \xi_{p}\right)\left(1-\xi_{p}\right)}{\left(1+\beta \gamma^{1-\sigma_{c} \iota_{p}}\right) \xi_{p}\left[\left(\phi_{p}-1\right) \epsilon_{p}+1\right]} \mu_{t}^{p}+a_{t}
$$

where $a_{t}$ is the cost-push shock, while $\iota_{p}$ denotes the degree of indexation to past inflation, $\xi_{p}$ is the degree of price stickiness, and $\epsilon_{p}$ is the curvature of the Kimball (1995) goods market aggregator. The rental rate of capital can be computed from

$$
r_{t}^{k}=-\left(k_{t}^{s}-l_{t}\right)+w_{t} .
$$

The definition of the wage markup $\mu_{t}^{w}$ is given by

$$
\mu_{t}^{w}=w_{t}-\left[\sigma_{l} l_{t}+\frac{1}{1-\frac{\lambda}{\gamma}}\left(c_{t}-\frac{\lambda}{\gamma} c_{t-1}\right)\right]
$$

where $\sigma_{l}$ denotes the elasticity of labor supply to the real wage. The wage Phillips curve is given by:

$$
\begin{aligned}
w_{t}= & \frac{1}{1+\beta \gamma^{1-\sigma_{c}}} w_{t-1}+\left(1-\frac{1}{1+\beta \gamma^{1-\sigma_{c}}}\right)\left(\mathrm{E}_{t} w_{t+1}+\mathrm{E}_{t} \pi_{t+1}\right) \\
& -\frac{1+\beta \gamma^{1-\sigma_{c}} \iota_{w}}{1+\beta \gamma^{1-\sigma_{c}}} \pi_{t}+\frac{\iota_{w}}{1+\beta \gamma^{1-\sigma_{c}}} \pi_{t-1} \\
& -\frac{\left(1-\beta \gamma^{1-\sigma_{c}} \xi_{w}\right)\left(1-\xi_{w}\right)}{\left(1+\beta \gamma^{1-\sigma_{c}}\right) \xi_{w}\left[\left(\phi_{w}-1\right) \epsilon_{w}+1\right]} \mu_{t}^{w}+b_{t}
\end{aligned}
$$

where $b_{t}$ is the wage markup disturbance, while $\iota_{w}$ denotes the degree of indexation to past wage inflation, $\xi_{w}$ is the degree of nominal wage stickiness, and $\epsilon_{w}$ is the curvature of the Kimball (1995) labor market aggregator. Finally, we use the Taylor (1993)-type monetary policy rule as

$$
r_{t}=\rho r_{t-1}+(1-\rho)\left(r_{\pi} \pi_{t}+r_{y} \Delta y_{t}\right)+m_{t}
$$

where $m_{t}$ is the monetary policy shock, while $\rho, r_{\pi}$ and $r_{y}$ are positive policy parameters. There are six exogenous disturbances in addition to the TFP shock in the system. These six additional 
driving forces are assumed to follow the following AR (1) processes:

$$
\begin{aligned}
f_{t} & =\rho_{f} f_{t-1}+\varepsilon_{t}^{f}, \quad \varepsilon_{t}^{f} \sim \text { i.i.d. } \quad N\left(0, \sigma_{f}^{2}\right), \\
g_{t} & =\rho_{g} g_{t-1}+\varepsilon_{t}^{g}, \quad \varepsilon_{t}^{g} \sim \text { i.i.d. } \quad N\left(0, \sigma_{g}^{2}\right), \\
v_{t} & =\rho_{v} v_{t-1}+\varepsilon_{t}^{v}, \quad \varepsilon_{t}^{v} \sim \text { i.i.d. } \quad N\left(0, \sigma_{v}^{2}\right), \\
m_{t} & =\rho_{m} m_{t-1}+\varepsilon_{t}^{m}, \quad \varepsilon_{t}^{m} \sim \text { i.i.d. } \quad N\left(0, \sigma_{m}^{2}\right), \\
a_{t} & =\rho_{a} a_{t-1}+\varepsilon_{t}^{a}, \quad \varepsilon_{t}^{a} \sim \text { i.i.d. } \quad N\left(0, \sigma_{a}^{2}\right), \text { and } \\
b_{t} & =\rho_{b} b_{t-1}+\varepsilon_{t}^{b}, \quad \varepsilon_{t}^{b} \sim \text { i.i.d. } N\left(0, \sigma_{b}^{2}\right) .
\end{aligned}
$$

Note that unlike the TFP shocks, each innovation term is given as a single component, implying that all the shocks are unanticipated. ${ }^{6}$

\section{$3 \quad$ Estimation Strategy}

We use Bayesian techniques to estimate the model parameters and to evaluate the importance of the news shocks. Bayesian estimation strategies help to estimate DSGE models with crossequation restrictions, coping well with misspecification and identification problems, and provide a coherent model evaluation procedure.

In solving a rational expectations system, we follow the approach of Sims (2002). ${ }^{7}$ In his approach, the log-linearized system can be written in the following canonical form:

$$
\Gamma_{0}(\theta) \mathbf{s}_{t}=\Gamma_{1}(\theta) \mathbf{s}_{t-1}+\Psi_{0}(\theta) \varepsilon_{t}+\Pi_{0}(\theta) \boldsymbol{\eta}_{t}
$$

where $\Gamma_{0}, \Gamma_{1}, \Psi_{0}$, and $\Pi_{0}$ are the conformable matrices of coefficients that depend on the structural parameters $\theta, \mathbf{s}_{t}$ is a stacked vector of endogenous variables including expectations at $t$, and $\varepsilon_{t}$ is a vector of fundamental shocks. $\boldsymbol{\eta}_{t}$ is a vector of endogenous forecast errors, defined as

$$
\boldsymbol{\eta}_{t}=\widehat{\mathbf{s}}_{t}-\mathrm{E}_{t-1} \widehat{\mathbf{s}}_{t}
$$

\footnotetext{
${ }^{6}$ Recent studies by Schmitt-Grohé and Uribe (2008) and Khan and Tsoukalas (2009) also consider the news component in the investment-specific technology shock, $v_{t}$, in addition to the TFP shocks. Milani and Treadwell (2009) introduce the news component in the monetary policy shock, $m_{t}$.

${ }^{7}$ Sims' solution method generalizes the technique in Blanchard and Kahn (1980).
} 
where $\widehat{\mathbf{s}}_{t}$ is a subvector of $\mathbf{s}_{t}$ that contains expectational variables. In the present model, $\widehat{\mathbf{s}}_{t}$ consists of $i_{t}, r_{t}^{k}, q_{t}, c_{t}, l_{t}, \pi_{t}$, and $w_{t}$. Note that the canonical representation of news shocks in (1) has been incorporated into the form (2). The solution is then given by ${ }^{8}$

$$
\mathbf{s}_{t}=\Gamma(\theta) \mathbf{s}_{t-1}+\Psi(\theta) \varepsilon_{t}
$$

Let $Y^{T}$ be a set of observable data. Since the rational expectations solution (3) and a set of measurement equations that relates data to the model variables $\mathbf{s}_{t}$ provide a state-space representation, the likelihood function $L\left(\theta \mid Y^{T}\right)$ can be evaluated using the Kalman filter. The Bayesian approach places a prior distribution $p(\theta)$ on parameters and updates the prior through the likelihood function. Bayes' Theorem provides the posterior distribution of $\theta$ :

$$
p\left(\theta \mid Y^{T}\right)=\frac{L\left(\theta \mid Y^{T}\right) p(\theta)}{\int L\left(\theta \mid Y^{T}\right) p(\theta) d \theta} .
$$

Markov Chain Monte Carlo methods are used to generate the draws from the posterior distribution. Based on the posterior draws, we can make an inference on the parameters. ${ }^{9}$ Details of its computational implementation are shown in Schorfheide (2000). The marginal data density, which assesses the overall fit of the model, is given by ${ }^{10}$

$$
p\left(Y^{T}\right)=\int L\left(\theta \mid Y^{T}\right) p(\theta) d \theta
$$

\section{Main Results}

We follow Smets and Wouters (2007) and use the data set consists of seven U.S. quarterly series: the log difference of real GDP; real consumption; real investment; and the real wage; the $\log$ of hours worked; the log difference of the GDP deflator; and the federal funds rate. ${ }^{11}$ Since the model contains $H+7$ exogenous shocks, it is exactly identified if there is no news shock $(H=0)$ and is over-identified in the presence of new shocks $(H>0)$. The model is estimated over the sample period from 1983:1 to $2004: 4 .^{12}$

\footnotetext{
${ }^{8}$ We consider only the parameter space that leads to equilibrium determinacy.

${ }^{9}$ For our subsequent analysis, 300,000 draws are generated with a random-walk Metropolis Algorithm, and the first 30,000 draws are discarded.

${ }^{10}$ The marginal data densities are approximated using the harmonic mean estimator proposed by Geweke (1999).

${ }^{11}$ For a detailed description of the data, see Smets and Wouters (2007).

${ }^{12}$ The beginning of the sample is determined to exclude the possibility of equilibrium indeterminacy, based on the finding in Clarida, Galí, and Gertler (2000) and Lubik and Schorfheide (2004).
} 
Prior distributions for the structural parameters are summarized in the first block of columns in Table 1. Most of the priors are similar to those in Smets and Wouters (2007) except for the news shocks that are not included in their analysis. Here, the standard deviations of news shocks, $\sigma_{z 1}, \sigma_{z 2}, \ldots, \sigma_{z H}$, are distributed around $H^{-1 / 2} \times \sigma_{z 0}$, so that $\sum_{h=1}^{H} \sigma_{z h}^{2}$, the variance of the total anticipated component $\nu_{t}^{*}$ in productivity, is equal to $\sigma_{z 0}^{2}$, the variance of unanticipated component $\nu_{0, t} \cdot{ }^{13}$

In this paper, we search for the news horizon $H$ using the following procedure. First, we set the maximum possible value of $H$ at 12 quarters. Then, we estimate the model for each $H \in\{0,1,2, \ldots, 12\}$ and select $H$ that provides the maximum marginal data density (4). As a result of this specification search, we select $H=5$ to be the optimal horizon.

The second block of columns in Table 1 reports the posterior distributions of the parameters under our baseline specification with news shocks. Basically, the posterior estimates are in line with those reported in Smets and Wouters (2007) including a highly persistence estimate of TFP shocks. The only exception is that our estimated degrees of wage and price stickiness are slightly lower than those in Smets and Wouters (2007). This difference may come from the introduction of the news shocks, or our AR (1) specification for all shocks instead of the ARMA specification used by Smets and Wouters (2007) for some shocks. Regarding the news shocks, the posterior distributions of their standard deviations are almost the same, irrespective of the news horizon. The similarity in variance of each news shock, however, does not imply that the role of the news shock for a different horizon is nearly equivalent, which is discussed later in this section.

Let us now use our estimated model and examine the importance of news shocks in the U.S. aggregate fluctuations in terms of the variance decomposition. To this end, we first classify shocks in the model into three subgroups: (i) an unanticipated (contemporaneous) TFP shock, $\nu_{0, t}$; (ii) news shocks in TFP, $\nu_{1, t}, \nu_{2, t}, \nu_{3, t}, \nu_{4, t}$, and $\nu_{5, t}$; and (iii) other six non-TFP shocks, $\varepsilon_{t}^{f}, \varepsilon_{t}^{g}, \varepsilon_{t}^{v}, \varepsilon_{t}^{m}, \varepsilon_{t}^{a}$ and $\varepsilon_{t}^{b}$. We then decompose the variance of each variable used in the estimation into components explained by three groups of shocks. In particular, we com-

\footnotetext{
${ }^{13}$ We use an equal weight on unexpected and expected TFP components in the prior distribution since there are no previous results of estimated DSGE models with news shocks available. The main results of the analysis, however, remain unchanged even if we set the prior weight on the unexpected shock as twice as large as the one on the news shock, or set the latter weight as twice as large as the former one.
} 
pute the forecast error variance decomposition evaluated at the infinite horizon by solving the dynamic Lyapunov-equation. The estimated relative contributions of each group of shocks to consumption, investment, output, hours worked, inflation, the real wage, and the interest rate are reported in Table 2.

An interesting finding here is that, on the whole, the contributions of the anticipated (news) components of the productivity shock to fluctuations of seven aggregate variables are somewhat comparable to those of the standard unanticipated (contemporaneous) technology shock. This finding is the first empirical evidence of the possibility of coexistence of these two types of shocks, under the fully specified DSGE modeling framework. The relative contribution of news shocks is generally higher for nominal variables (inflation, wage and interest rate) than for real variables (consumption, investment, output and hours). The presence of news shocks is also supported when we compare the variance decompositions with those based on the model under the assumption of no news shock, namely the case of $H=0$, obtained in the previous specification search procedure. Since there are only an unanticipated TFP shock and non-TFP shocks when there is no news shock, the variance decomposition of each variable into two corresponding components is also reported in Table 2 along with the result of the baseline specification. For all seven variables, the contribution of the (unanticipated) TFP shocks is smaller when news shocks are excluded from the model. In addition, for all variables, the estimated contribution of the group of news shocks in the baseline model is larger than that of the (unanticipated) TFP shocks when news shocks are excluded. As a result, the total contribution of TFP related shocks, $\varepsilon_{t}^{z}=\sum_{h=0}^{H} \nu_{h, t-h}$, in the baseline specification is much larger in the presence of news shocks, than in the case of no news shocks.

The effect of the news shocks on the productivity in our estimated model can be also understood from the impulse responses in Figure 1. The figure depicts the impulse responses of seven aggregate series to one-standard-deviation unanticipated TFP shocks and news shocks on TFP at horizons 1, 3 and 5. In the present model with the habit persistence in consumption, adjustment cost in investment and nominal rigidities, hours worked decrease for a positive unanticipated productivity shock, while consumption and investment increase. Thus, in the 
absence of news shocks, our model cannot generate observed procyclical labor. On the other hand, the impulse responses to the news shocks in Figure 1 imply that a news shock can generate the comovement among consumption, investment, and hours worked. For this reason, to match the observed procyclical labor, news shocks need to make some contribution in aggregate fluctuations.

Another interesting observation from Figure 1 involves the asymmetric responses of nominal variables to the news shocks with different forecast horizons. When the forecast horizon of the news shock becomes longer, the effects of the news shock become larger on nominal than on real variables. This outcome also reflects the discussions above. The hours worked, and therefore the marginal cost, increase up until the expectation actually materializes. At the same time, for the longer forecast horizon, the present discounted value of the reduction in the marginal cost becomes smaller. Consequently, the changes in expectation at the longer horizon have more impact on nominal variables. ${ }^{14}$

The first column of Table 3 reports the relative contribution of news shock at each horizon to the variances of output and inflation. The relative contributions of news shocks do not seem to decrease with the horizon for the output. In contrast, they significantly increase with the horizon for the inflation, a nominal variable. So far, in the studies on the news shocks, such as Beaudry and Portier (2004), Jaimovich and Rebelo (2009), Denhaan and Kaltenbrunner (2007), Kobayashi, Nakajima, and Inaba (2007), Beaudry, Collard, and Portier (2006), and Christiano, Ilut, Motto, and Rostagno (2008), the theoretical responses to the news shocks are analyzed for some arbitrary forecast horizon. To the best of our knowledge, however, the sensitivity of responses to changes in the forecast horizon has never been systematically examined.

\section{Discussions}

\subsection{Sensitivity Analysis}

\section{Multiple news shocks and a single news shock}

In our analysis, we specify a model with multiple news shocks in the TFP. We can also

\footnotetext{
${ }^{14}$ Yet this relationship is not monotonic. As the forecast horizon becomes longer, the wealth effects on current consumption and leisure become stronger. As a result, this effect can result in the further reduction of the marginal cost.
} 
compare models with only a single news shock in the TFP to the baseline model with multiple news shocks as well as the no news case considered in the previous section. In Table 3, the contributions of the single news shock to the variances of output and inflation, along with the corresponding marginal likelihood, are provided. Each alternative specification includes only one from $\nu_{1, t}, \nu_{2, t}, \nu_{3, t}, \nu_{4, t}$ and $\nu_{5, t}$ in addition to an unanticipated shock $\nu_{0, t}$. We can point out several intriguing findings from Table 3. In each case, the contributions of the news shock are non-negligible but smaller in magnitude compared to the baseline estimate. Furthermore, none of additional cases with a single news shock dominate the baseline model in terms of the marginal data density. These results demonstrate the importance of including multiple news shocks to explain aggregate fluctuations.

\section{Transitory news shocks and permanent news shocks}

In our analysis, the TFP is assumed to be generated from a stationary $\operatorname{AR}(1)$ process around the (linear) deterministic trend following the specification employed in Smets and Wouters (2003, 2007). While our estimated AR coefficient suggests that the TFP shocks are highly persistent, our specification does not allow the TFP shock to have a permanent effect. In the literature of news shocks, the effects of an anticipated permanent change in the TFP are often discussed. In the bivariate VAR approach of Beaudry and Portier (2006), news shocks are identified under the assumption of a stochastic trend in the TFP. Also, in a recent study by Schmitt-Grohé and Uribe (2008), which is conducted independently of ours, both stationary and nonstationary shock components in the TFP are introduced in a flexible price DSGE model. Instead of estimating a model with a nonstationary TFP, let us here compare our results with other studies that incorporate permanent TFP shocks. According to Schmitt-Grohé and Uribe (2008), the VAR results of Beaudry and Portier (2006) imply that the contribution of (permanent) news shocks in the forecast error variance of output growth at a 30-quarter horizon varies from 55 to 75 percent, depending on the choice of the identification scheme. Based on a DSGE model estimated by Schmitt-Grohé and Uribe (2008), a permanent TFP news shock accounts for 31 percent of output growth fluctuation, while a permanent TFP unanticipated shock only accounts for 2 percent. On the other hand, contributions of stationary TFP news and unanticipated shocks 
are 28 and 37 percent, respectively. In contrast, our stationary TFP news and unanticipated shocks, respectively, account for 12 and 9 percent of output fluctuation around the deterministic trend. While our estimates are somewhat smaller in magnitude than those in the other studies, the difference is mainly due to the presence of six additional non-TFP shocks in our CEEtype DSGE model. By construction, the bivariate VAR approach cannot identify more than two shocks. Also, TFP-related shocks altogether accounts for $98 \%$ of output growth variation in the analysis of Schmitt-Grohé and Uribe (2008) most likely because some of the important non-TFP shocks in our estimates are not included. In summary, it seems safe to say that the contribution of the news shocks in business cycles is non-negligible under both the stationary and nonstationary assumptions of the TFP.

\subsection{Technology Shocks and Hours Worked Revisited}

Let us now discuss the implication of our estimates for a controversial issue of the response of hours worked to a technology shock. In standard real business cycle models, hours should rise after a positive technology shock. However, Galí (1999) showed empirically that technology shocks identified from a structural VAR model have a negative effect on hours. He pointed out that the negative correlation between a technology shock and hours was consistent with a model with monopolistic competition and sticky prices. His view was later confirmed by Francis and Ramey (2005), who employed a structural VAR model using alternative identifying restrictions, and by Smets and Wouters (2007), who conducted a Bayesian estimation of a DSGE model with nominal price rigidities. In sharp contrast, Christiano, Eichenbaum, and Vigfusson (2003) provided the evidence of positive correlation between a technology shock and hours and claimed that the previous findings of a positive correlation might have been caused by misspecifications in the estimation. In particular, opposite results could be obtained by estimating a structural VAR model with identifying assumptions very similar to that of Galí (1999) and Francis and Ramey (2005), but allowing for the stationarity of hours worked.

Our estimates offer one possible solution to reconciling the two competing views regarding the sign of the correlation between the technology shock and hours. Recall that there are two components in the technology shock $\varepsilon_{t}^{z}$; one is the contemporaneous (unanticipated) component 
$\nu_{0, t}$ and the other is the news component $\nu_{t}^{*}=\sum_{h=1}^{5} \nu_{h, t-h}$. As shown in Figure 1, each of the two components of the technology shock has an instantaneous effect on hours worked in the opposite direction. When all the technology disturbances are unanticipated, so that $\varepsilon_{t}^{z}=\nu_{0, t}$, the technology shock has an immediate and significant negative impact on the hours worked, thus our results strongly support the findings by Galí (1999), Francis and Ramey (2005), and Smets and Wouters (2007). In contrast, the same figure shows that the impact responses of hours worked to news shocks $\nu_{h, t}, h=1, \ldots, 5$, are positive and significant. Because of this offsetting role of the news shocks, the overall effect of the broadly defined technology shock can become ambiguous. To confirm this conjecture, let us conduct a simple experiment by generating simultaneous positive shocks on both contemporaneous and news components. The weighted sum of each impulse response, weighted by $\sigma_{z h}$ for $h=0,1, \ldots, 5$, is then interpreted as the total effect. The upper half of Figure 2 shows the responses of output, hours worked and productivity to such a composite shock. The lower half shows the response to the unanticipated shock $\nu_{0, t}$ using the model estimated under the assumption of no news shock. Note that the hour response is significantly negative in the latter case. In contrast, the immediate response of hours in the baseline is almost zero with its confidence band covering both positive and negative regions. This outcome suggests that the overall effect can be either positive or negative if we employ a broader, but somewhat atypical, definition of a "technology shock."

Finally, the same reasoning can be also used as a possible explanation of the well-known productivity-hours anomaly, namely, the empirical observation of near-zero (or negative) correlation between productivity and hours worked. By comparing the impulse responses of hours worked and productivity in Figure 2, the broadly defined "technology shock" generates a nearzero comovement between the two. The mechanism behind this result is identical to that of Galí (1999), who claimed that (unanticipated) TFP shocks generate a negative comovement between two variables rather than the positive one predicted in the standard real business cycle models. To offset this effect, however, positive comovement is generated from news shocks here, while Galí (1999) relied on non-technology shocks (such as monetary shocks). In the presence of the news component, the technology shock alone may account for the productivity-hours anomaly. 


\subsection{An International Comparison: U.S. and Japan}

In the discussion of Japan's lost decade in 1990s, Hayashi and Prescott (2002) pointed out the importance of news shocks by suggesting that "the unusual pickup in economic activities, particularly investment, was due to an anticipation of higher productivity growth that never materialized (p.228)." ${ }^{15}$ In addition, the correlation between technology shocks and hours worked remains an unsettled question in Japan. For example, while Galí (2005) and Braun and Shioji (2004) showed the correlation to be positive, Watanabe (2006) claimed a near-zero correlation. In this subsection, we estimate the same CEE-type DSGE model with news shocks in TFP using Japanese data and compare the result with that of the U.S.

We follow Sugo and Ueda (2008) who estimated a similar CEE-type DSGE model for Japan, in the construction of the data. The GDP deflator and the federal funds rate used in the U.S. analysis are replaced by the CPI and the overnight call rate. We also allow deterministic trend breaks in 1991:2 and 2001:1. The model is estimated over the sample period from 1981:2 to 1998:4 for Japan. ${ }^{16}$

The main results from the estimation are summarized as follows. First, in contrast to the U.S. result, the fit of the model does not significantly improve by the addition of news shocks. When the same procedure is used to search for the news horizon, $H=0$ is selected. Table 4 shows the marginal data densities of Japanese data for various specifications used in Table 3 for the U.S. Nevertheless, Tables 3 and 4 suggest that estimated contribution of each news shocks are comparable between two countries. In some cases of a single news shock, the magnitude is indeed higher in Japan than in the U.S.

Second, the contribution of news shocks relative to that of the unanticipated shock is very small in explaining the output fluctuation as shown in Table 4. This outcome is in contrast to the U.S. result where two types of shocks contribute almost equally to the variation in output. This difference is mainly due to the fact that an unanticipated TFP shock alone can account

\footnotetext{
${ }^{15}$ Christiano and Fujiwara (2006) also argued that the news shock can be a potential candidate for the explanation of the bubble in Japan based on the calibrated model.

${ }^{16}$ The end of the sample period is determined in order not to include the period during which the zero nominal interest rate policy is adopted by the Bank of Japan. Our view is that the period with the zero bound on the nominal interest rate should be dealt with separately due to nonlinearity of the policy rules.
} 
for about half the total output variance even if news shocks are excluded from the specification. This observation is consistent with the previous DSGE estimation result without incorporating news shocks. Sugo and Ueda (2008) report that the majority of the output fluctuation can be accounted for by the unanticipated TFP shocks in the Japanese economy, while Smets and Wouters (2007) show that the contribution of unanticipated TFP shocks to output fluctuation is between 15 to 30 percent in the U.S. economy.

Finally, we point out that, while evidence for Japan is not as strong as that for the U.S., our estimates with $H=5$ suggest that a longer forecast horizon had larger effects on nominal variables, and that the overall effect of the TFP on hours worked became ambiguous. Again, these findings cannot be obtained from the bivariate VAR approach used by Beaudry and Portier (2005) to identify the news shock in Japanese economy.

\section{Conclusion}

In this paper, we have examined the role of news shocks in the aggregate fluctuations. Our Bayesian estimates of the canonical sticky price DSGE model suggested that news shocks have played a relatively more important role in the U.S. business cycles than Japanese business cycles. We also found that a news shock with a longer forecast horizon had larger effects on nominal variables, and that the overall effect of the TFP on hours worked became ambiguous in the presence of news shocks.

Possible future extensions of our approach include introducing news shocks to innovations other than TFP, and allowing for correlation between unanticipated shocks and news shocks. It may be possible to derive a different interpretation of wedges stemming from the TFP by allowing multiple forecast horizons in the news shocks introduced in our paper in the business cycle accounting approach of Chari, Kehoe, and McGrattan (2007). Furthermore, the standard CEE-type model may lack some important mechanisms such as the ones emphasized in the financial accelerator model of Bernanke, Gertler, and Gilchrist (1999). It is left for our future research to understand the contributions of news shocks in a model that incorporates the financial sector. 


\section{Appendix}

This appendix summarizes a simplified model of Smets and Wouters $(2003,2007)$ that we estimate along with news shocks. Five agents in the model are: households; the final goods producer; the intermediate goods producers; the intermediate labor union; and the central bank. We first show the optimizing problem or the rule for each agent and then derive the equilibrium conditions.

\section{A.1. Households}

Household $j$ chooses consumption $C_{t}(j)$, hours worked $L_{t}(j)$, bonds $B_{t}(j)$, investment $I_{t}(j)$, and capital utilization $u_{t}(j)$ to maximize the following welfare:

$$
\mathrm{E}_{0} \sum_{t=0}^{\infty} \beta^{t} \frac{\left[C_{t}(j)-\lambda C_{t-1}\right]^{1-\sigma_{c}}}{1-\sigma_{c}} \exp \left[\frac{\sigma_{c}-1}{1+\sigma_{l}} L_{t}^{1+\sigma_{l}}(j)\right],
$$

subject to the budget constraint:

$$
\begin{aligned}
C_{t}(j)+I_{t}(j)+\frac{B_{t}(j)}{R_{t} P_{t}}-T_{t} \leq & \frac{B_{t-1}(j)}{P_{t}}+\frac{W_{t}(j) L_{t}(j)}{P_{t}}+\frac{R_{t}^{k} u_{t}(j) K_{t-1}(j)}{P_{t}} \\
& -a\left[u_{t}(j) ; \psi\right] K_{t-1}(j)+\frac{D_{t}}{P_{t}}
\end{aligned}
$$

and the capital formation:

$$
K_{t}(j)=(1-\delta) K_{t-1}(j)+\left\{1-S\left[\frac{I_{t}(j)}{I_{t-1}(j)} ; \varphi\right]\right\} I_{t}(j)
$$

where $T_{t}$ is the lump-sum tax, $P_{t}$ is the consumer price level, $R_{t}^{k}$ is the cost of capital, $\Pi_{t}$ is the dividend from firms, $a[x ; \psi]$ is the cost function of changing the capacity utilization and $S[x ; \varphi]$ is the cost function of changing the investment satisfying $S[\gamma ; \varphi]=S^{\prime}[\gamma ; \varphi]=0$ and $S^{\prime \prime}>0$.

\section{A.2. Final Goods Producer}

The final goods producer maximizes the profit

$$
P_{t} Y_{t}-\int_{0}^{1} P_{t}(i) Y_{t}(i) \mathrm{d} i
$$

subject to the aggregating technology:

$$
\int_{0}^{1} G\left[\frac{Y_{t}(i)}{Y_{t}} ; \epsilon_{p}\right] \mathrm{d} i=1
$$

where $Y_{t}$ and $Y_{t}(i)$ are the final and intermediate goods, respectively, $P_{t}(i)$ is the intermediate goods price, and $G\left[x ; \epsilon_{p}\right]$ is the Kimball (1995) aggregator.

\section{A.3. Intermediate Goods Producers}

The marginal cost $M C_{t}(i)$, which the intermediate goods producer $i$ faces, is computed as the Lagrange multiplier from the following cost minimization problem:

$$
\min _{W_{t}(i), L_{t}(i)} W_{t}(i) L_{t}(i)+R_{t}^{k} K_{t}(i),
$$


subject to the production function

$$
Y_{t}(i)=K_{t}^{s}(i)^{\alpha}\left[\gamma^{t} L_{t}(i)\right]^{1-\alpha}-\gamma^{t} \Phi,
$$

where $\Phi$ is a fixed cost of production, and the current capital services in production given by

$$
K_{t}^{s}(i)=u_{t}(i) K_{t-1}(i) \text {. }
$$

Using the marginal cost defined above, the intermediate goods firm $i$, with Calvo type frictions, chooses the newly set price $\tilde{P}_{t}(i)$ by maximizing the presented discounted value of profit:

$$
\mathrm{E}_{t} \sum_{\tau=0}^{\infty} \xi_{p}^{\tau} \beta^{\tau} m_{t, \tau}\left[\tilde{P}_{t}(i)\left(\prod_{n=1}^{\tau} \pi_{t+n-1}^{\iota_{p}} \pi_{*}^{1-\iota_{p}}\right)-M C_{t+n}\right] Y_{t+\tau}(i),
$$

subject to the demand function:

$$
Y_{t+\tau}(i)=G^{\prime-1}\left[\frac{\tilde{P}_{t}(i) \prod_{n=1}^{\tau} \pi_{t+n-1}^{\iota_{p}} \pi_{*}^{1-\iota_{p}}}{P_{t+\tau}} \int_{0}^{1} G^{\prime}\left(\frac{Y_{t+\tau}(i)}{Y_{t+\tau}}\right) \frac{Y_{t+\tau}(i)}{Y_{t+\tau}} \mathrm{d} i\right]
$$

where $m_{t, \tau}$ is the stochastic discount factor that is defined as the intertemporal ratio of marginal utility out of consumption.

\section{A.4. Intermediate Labor Union}

The intermediate labor union first collects the homogenous labor supplied from households. It then differentiates labor services denoted by $l$ and offers wages to firms. Under flexible wage setting, the desired wage $W_{t}^{h}$ is determined by the household optimality conditions for labor supply which is same for all households. Here, the intermediate labor union faces Calvo-type frictions, and thus sets the wage $\tilde{W}_{t}(l)$ by maximinzing:

$$
\mathrm{E}_{t} \sum_{\tau=0}^{\infty} \xi_{w}^{\tau} \beta^{\tau} m_{t, \tau}\left[W_{t+\tau}(l)-W_{t+\tau}^{h}\right] L_{t+\tau}(l),
$$

subject to the labor demand function:

$$
L_{t+\tau}(l)=\left[\frac{W_{t+\tau}(l)}{W_{t+\tau}}\right]^{-\frac{1+\lambda_{w}}{\lambda_{w}}} L_{t+\tau},
$$

and the trend in nominal wage growth:

$$
W_{t+\tau}(l)=\tilde{W}_{t}(l)\left(\prod_{n=1}^{\tau} \pi_{t+n-1}^{\iota_{w}} \pi_{*}^{1-\iota_{w}}\right) .
$$

\section{A.5. The Central Bank}

The central bank sets the short-term nominal interest rate by following the simple instrument rule:

$$
\frac{R_{t}}{R^{*}}=\left(\frac{R_{t-1}}{R^{*}}\right)^{\rho}\left[\left(\frac{\pi_{t}}{\pi^{*}}\right)^{r_{\pi}}\left(\frac{Y_{t}}{Y_{t-1}} \frac{Y_{t-1}^{*}}{Y_{t}^{*}}\right)^{r_{y}}\right]^{1-\rho}
$$

where $Y_{t}^{*}$ is the natural output, which is defined as the output in the flexible price and wage equilibrium. 


\section{A.6. Equilibrium Conditions}

We detrend the equilibrium conditions in level as follows:

$$
\begin{aligned}
k_{t} & =\frac{K_{t}}{\gamma^{t}}, k_{t}^{s}=\frac{K_{t}^{s}}{\gamma^{t}}, w_{t}=\frac{W_{t}}{P_{t} \gamma^{t}}, r_{t}^{k}=\frac{R_{t}^{k}}{P_{t}}, c_{t}=\frac{K_{t}}{\gamma^{t}}, \\
\pi_{t} & =\frac{P_{t}}{P_{t-1}}, c_{t}=\frac{K_{t}}{\gamma^{t}}, i_{t}=\frac{I_{t}}{\gamma^{t}}, y_{t}=\frac{Y_{t}}{\gamma^{t}}, m c_{t}=\frac{M C_{t}}{P_{t}}=\frac{1}{\mu_{t}^{p}} .
\end{aligned}
$$

We assume ex post symmetric equilibrium for the equilibrium conditions below. Equation (A1) can be transformed into

$$
k_{t}=(1-\delta) \frac{1}{\gamma} k_{t-1}+\left[1-S\left(\frac{\gamma i_{t}}{i_{t-1}}\right)\right] i_{t} .
$$

Equation, (A2), (A3) and (A4) are also detrended as

$$
\begin{gathered}
y_{t}=\left(k_{t}^{s}\right)^{\alpha} L_{t}(i)^{1-\alpha}-\Phi, \\
k_{t}^{s}=\frac{u_{t}}{\gamma} k_{t-1},
\end{gathered}
$$

and

$$
\frac{R_{t}}{R^{*}}=\left(\frac{R_{t-1}}{R^{*}}\right)^{\rho}\left[\left(\frac{\pi_{t}}{\pi^{*}}\right)^{r_{\pi}}\left(\frac{y_{t}}{y_{t-1}} \frac{y_{t-1}^{*}}{y_{t}^{*}}\right)^{r_{y}}\right]^{1-\rho} .
$$

The resource constraint in this economy is given by

$$
y_{t}=c_{t}+i_{t}+\frac{a\left(u_{t}\right)}{\gamma} k_{t-1}
$$

From household's first order necessary conditions, we can derive

$$
\begin{gathered}
\left(c_{t}-\frac{\lambda}{\gamma} c_{t-1}\right)^{-\sigma_{c}} \exp \left(\frac{\sigma_{c}-1}{1+\sigma_{l}} L_{t}^{1+\sigma_{l}}\right)=\beta \frac{R_{t}}{\pi_{t+1}}\left(\gamma c_{t+1}-\lambda c_{t}\right)^{-\sigma_{c}} \exp \left(\frac{\sigma_{c}-1}{1+\sigma_{l}} L_{t+1}^{1+\sigma_{l}}\right), \\
r_{t}^{k} k_{t-1}=a^{\prime}\left(u_{t}\right) k_{t-1}, \\
q_{t}=\beta \frac{\left(\gamma c_{t+1}-\lambda c_{t}\right)^{-\sigma_{c}} \exp \left(\frac{\sigma_{c}-1}{1+\sigma_{l}} L_{t+1}^{1+\sigma_{l}}\right)}{\left(c_{t}-\frac{\lambda}{\gamma} c_{t-1}\right)^{-\sigma_{c}} \exp \left(\frac{\sigma_{c}-1}{1+\sigma_{l}} L_{t}^{1+\sigma_{l}}\right)}\left[r_{t+1}^{k} u_{t+1}-a\left(u_{t+1}\right)+q_{t+1}(1-\delta)\right],
\end{gathered}
$$

and

$$
q_{t}=\frac{1-\beta \frac{\left(\gamma c_{t+1}-\lambda c_{t}\right)^{-\sigma_{c}} \exp \left(\frac{\sigma_{c}-1}{1+\sigma_{l}} L_{t+1}^{1+\sigma_{l}}\right)}{\left(c_{t}-\frac{\lambda}{\gamma} c_{t-1}\right)^{-\sigma_{c}} \exp \left(\frac{\sigma_{c}-1}{1+\sigma_{l}} L_{t}^{1+\sigma_{l}}\right)} q_{t+1} S^{\prime}\left(\frac{\gamma i_{t+1}}{i_{t}}\right)\left(\frac{\gamma i_{t+1}}{i_{t}}\right)^{2}}{1-S\left(\frac{\gamma i_{t}}{i_{t-1}}\right)-S^{\prime}\left(\frac{\gamma i_{t}}{i_{t-1}}\right) \frac{\gamma i_{t}}{i_{t-1}}}
$$

where $q_{t}$ is the theoretical price of capital, which is the ratio of the Lagrange multiplier on the capital formation over that on the budget constraint.

From the cost minimization problem by intermediate goods producers, we can derive

$$
k_{t}^{s}=\frac{\alpha}{1-\alpha} \frac{w_{t}}{r_{t}^{k}} L_{t}
$$

and

$$
\begin{aligned}
m c_{t} & =\frac{1}{\mu_{t}^{p}}=\left(\frac{r_{t}^{k}}{\alpha}\right)^{\alpha}\left[\frac{w_{t}}{(1-\alpha)}\right]^{1-\alpha} \\
& =\frac{w_{t}}{1-\alpha}\left(\frac{L_{t}}{k_{t}^{s}}\right)^{\alpha} .
\end{aligned}
$$


Furthermore, from the optimal labor supply decision by households, we have

$$
\left(c_{t}-\frac{\lambda}{\gamma} c_{t-1}\right) L_{t}^{\sigma_{l}}(j)=\frac{P_{t} \gamma^{t} w_{t}}{P_{t} \gamma^{t} w_{t}} \frac{W_{t}^{h}}{\gamma^{t} P_{t}}=\frac{w_{t}^{h}}{w_{t}} w_{t}=\frac{1}{\mu_{t}^{w}} w_{t}
$$

where we detrend the flexible desired wage using

$$
w_{t}^{h}=\frac{W_{t}^{h}}{\gamma^{t} P_{t}} .
$$

The rests are optimality conditions from staggered price and wage settings. From the optimal price setting problem, we have

$$
\begin{aligned}
& \frac{1}{\lambda_{p}}\left[\tilde{p}_{t}-\left(1+\lambda_{p}\right) m c_{t}\right] y_{t} \\
& +\mathrm{E}_{t} \sum_{\tau=0}^{\infty} \frac{\xi_{p}^{\tau} \beta^{\tau} \gamma^{\tau+\sigma_{c}} m_{t, \tau}}{\lambda_{p}}\left[\tilde{p}_{t} \frac{\prod_{n=1}^{\tau} \pi_{t+n-1}^{\iota_{p}} \pi_{*}^{1-\iota_{p}}}{\prod_{n=1}^{\tau} \pi_{t+n}}-\left(1+\lambda_{p}\right) m c_{t+\tau}\right] y_{t+\tau} \\
= & 0,
\end{aligned}
$$

where we define

$$
\tilde{p}_{t}=\frac{\tilde{P}_{t}}{P_{t}}
$$

Similarly, for the optimal wage setting, we can derive

$$
\mathrm{E}_{t} \sum_{\tau=0}^{\infty} \frac{\xi_{w}^{\tau} \beta^{\tau} \gamma^{\tau+\sigma_{c}} m_{t, \tau}}{\lambda_{w}}\left[\left(1+\lambda_{w}\right) w_{t+\tau}^{h}-\frac{\prod_{n=1}^{\tau} \pi_{t+n-1}^{\iota_{w}} \pi_{*}^{1-\iota_{w}}}{\prod_{n=1}^{\tau} \pi_{t+n-1}} \tilde{w}_{t}\right]=0
$$

where we define

$$
\tilde{w}_{t}=\frac{\tilde{W}_{t}}{\gamma^{t} P_{t}}
$$

By log-linearizing the equations (A5) to (A18) around the steady state, we can obtain the 14 linearized equilibrium conditions used in the main text. We can eliminate the newly set price and wage, namely $\tilde{p}_{t}$ and $\tilde{w}_{t}$ by log-linearization. 


\section{References}

Adolfson, Malin, Stefan Laseen, Jesper Linde, and Mattias Villani (2007). "Bayesian Estimation of an Open Economy DSGE Model with Incomplete Pass-Through." Journal of International Economics, 72(2), 481-511.

Barro, Robert J., and Robert G. King (1984). "Time-Separable Preferences and IntertemporalSubstitution Models of Business Cycles." The Quarterly Journal of Economics, 99(4), 817839.

Beaudry, Paul, Fabrice Collard, and Franck Portier (2006). "Gold Rush Fever in Business Cycles." NBER Working Paper 12710, National Bureau of Economic Research.

Beaudry, Paul, and Franck Portier (2004). "An Exploration into Pigou's Theory of Cycles." Journal of Monetary Economics, 51(6), 1183-1216.

Beaudry, Paul, and Franck Portier (2005). "The 'News View' of Economic Fluctuations: Evidence from Aggregate Japanese Data and Sectoral US Data." Journal of the Japanese and International Economies, 191(4), 635-652.

Beaudry, Paul, and Franck Portier (2006). "Stock Prices, News, and Economic Fluctuations." American Economic Review, 96(4), 1293-1307.

Bernanke, Ben S., Mark Gertler, and Simon Gilchrist (1999). "The Financial Accelerator in a Quantitative Business Cycle Framework." In Handbook of Macroeconomics Vol. 1, edited by John. B. Taylor, and Michael Woodford, pp. 1341-1393. Elsevier.

Blanchard, Olivier Jean, and Charles M. Kahn (1980). "The Solution of Linear Difference Models under Rational Expectations." Econometrica, 48(5), 1305-1311.

Braun, R. Anton, and Etsuro Shioji (2004). "Nihon ni okeru Gijutsuteki Shokku to Sorodo-Jikan (Effects of Technology Shocks on Hours Worked in Japan)." Keizai Kenkyuu, 55, 289-298 (in Japanese). 
Chari, V. V., Patrick J. Kehoe, and Ellen R. McGrattan (2007). "Business Cycle Accounting." Econometrica, 75(3), 781-836.

Christiano, Lawrence, Cosmin Ilut, Roberto Motto, and Massimo Rostagno (2008). "Monetary Policy and Stock Market Boom-Bust Cycles." Working Paper Series 955, European Central Bank.

Christiano, Lawrence J., Martin Eichenbaum, and Charles L. Evans (2005). "Nominal Rigidities and the Dynamic Effects of a Shock to Monetary Policy." Journal of Political Economy, 113(1), 1-45.

Christiano, Lawrence J., Martin Eichenbaum, and Robert Vigfusson (2003). "What Happens after a Technology Shock?." NBER Working Paper 9819, National Bureau of Economic Research.

Christiano, Lawrence J., and Ippei Fujiwara (2006). "Baburu Kajo-Toshi Jitan UshinawaretaJu-Nen (Bubble, Overinvestment, Reduction in Working Hours, and the Lost Decade)." Bank of Japan Working Paper 06-J-08, Bank of Japan (in Japanese).

Clarida, Richard, Jordi Galí, and Mark Gertler (2000). "Monetary Policy Rules and Macroeconomic Stability: Evidence and Some Theory." Quarterly Journal of Economics, 115(1), $147-180$.

Denhaan, Wouter, and Georg Kaltenbrunner (2007). "Anticipated Growth and Business Cycles in Matching Models." Mimeo, London Business School.

Erceg, Christopher J., Luca Guerrieri, and Christopher Gust (2006). "SIGMA: A New Open Economy Model for Policy Analysis." International Journal of Central Banking, 2(1).

Francis, Neville, and Valerie A. Ramey (2005). "Is the Technology-Driven Real Business Cycle Hypothesis Dead? Shocks and Aggregate Fluctuations Revisited." Journal of Monetary Economics, 52(8), 1379-1399.

Fujiwara, Ippei (2007). "A Note on Growth Expectation." Macroeconomic Dynamics, Forthcoming. 
Fujiwara, Ippei, and Heedon Kang (2006). "Expectation Shock Simulation with DYNARE." QM\&RBC Codes, Quantitative Macroeconomics \& Real Business Cycles, available at http://ideas.repec.org/c/dge/qmrbcd/163.html.

Galí, Jordi (1999). "Technology, Employment, and the Business Cycle: Do Technology Shocks Explain Aggregate Fluctuations?." American Economic Review, 89(1), 249-271.

Galí, Jordi (2005). "Trends in Hours, Balanced Growth, and the Role of Technology in the Business Cycles." The Federal Reserve Bank of St. Louis Review, pp. 459-486.

Geweke, John F. (1999). "Using Simulation Methods for Bayesian Econometric Models: Inference, Development and Communication." Econometric Reviews, 18(1), 1-126.

Hayashi, Fumio, and Edward C. Prescott (2002). "The 1990s in Japan: A Lost Decade." Review of Economic Dynamics, 5(1), 206-235.

Jaimovich, Nir, and Sergio Rebelo (2009). "Can News about the Future Drive the Business Cycle?." American Economic Review, 99(4), 1097-1118.

Khan, Hashmat, and John Tsoukalas (2009). "The Quantitative Importance of News Shocks in Estimated DSGE Models.” Mimeo, Carleton University.

Kimball, Miles S (1995). "The Quantitative Analytics of the Basic Neomonetarist Model." Journal of Money, Credit and Banking, 27(4), 1241-1277.

Kobayashi, Keiichiro, Tomoyuki Nakajima, and Masaru Inaba (2007). "Collateral Constraint and News-Driven Cycles." Discussion Paper 07013, Research Institute of Economy, Trade and Industry (RIETI).

Laxton, Douglas, and Paolo Pesenti (2003). "Monetary Rules for Small, Open, Emerging Economies." Journal of Monetary Economics, 50(5), 1109-1146.

Lubik, Thomas A., and Frank Schorfheide (2004). "Testing for Indeterminacy: An Application to U.S. Monetary Policy." American Economic Review, 94(1), 190-217. 
Milani, Fabio, and John Treadwell (2009). "The Effects of Monetary Policy "News" and "Surprises"." Mimeo, University of California, Irvine.

Pigou, Arthur C. (1926). Industrial Fluctuations. London: MacMillan and Co.

Schmitt-Grohé, Stephanie, and Martín Uribe (2008). "What's News in Business Cycles." Working Paper 14215, National Bureau of Economic Research.

Schorfheide, Frank (2000). "Loss Function-Based Evaluation of DSGE Models." Journal of Applied Econometrics, 15(6), 645-670.

Sims, Christopher A. (2002). "Solving Linear Rational Expectations Models." Computational Economics, 20(1-2), 1-20.

Smets, Frank, and Raf Wouters (2003). "An Estimated Dynamic Stochastic General Equilibrium Model of the Euro Area." Journal of the European Economic Association, 1(5), 1123-1175.

Smets, Frank, and Rafael Wouters (2007). "Shocks and Frictions in US Business Cycles: A Bayesian DSGE Approach." American Economic Review, 97(3), 586-606.

Sugo, Tomohiro, and Kozo Ueda (2008). "Estimating a Dynamic Stochastic General Equilibrium Model for Japan." Journal of the Japanese and International Economies, 22(4), 476-502.

Taylor, John B. (1993). "Discretion versus Policy Rules in Practice." Carnegie-Rochester Conference Series on Public Policy, 39, 195-214.

Watanabe, Shingo (2006). "Roles of Technology and Nontechnology Shocks in the Business Cycles." Bank of Japan Working Paper 06-E-11, Bank of Japan. 
Table 1: Prior and Posterior Distributions of the Parameters

\begin{tabular}{|c|c|c|c|c|c|c|}
\hline \multirow[b]{2}{*}{ Parameter } & \multirow[b]{2}{*}{ Range } & \multicolumn{3}{|c|}{ Prior Distributions } & \multicolumn{2}{|c|}{ Posterior Distributions } \\
\hline & & Density & Mean & $90 \%$ Interval & Mean & $90 \%$ Interval \\
\hline$\varphi$ & $\Re^{+}$ & Normal & 4.00 & {$[1.58,6.48]$} & 4.82 & {$[2.67,6.97]$} \\
\hline$\sigma_{c}$ & $\Re^{+}$ & Normal & 1.50 & {$[1.17,1.83]$} & 1.72 & {$[1.50,1.93]$} \\
\hline$\lambda$ & {$[0,1)$} & Beta & 0.70 & {$[0.55,0.87]$} & 0.38 & {$[0.30,0.46]$} \\
\hline$\xi_{w}$ & {$[0,1)$} & Beta & 0.50 & {$[0.33,0.67]$} & 0.26 & {$[0.17,0.35]$} \\
\hline$\sigma_{l}$ & $\Re^{+}$ & Normal & 2.00 & {$[0.79,3.26]$} & 2.23 & {$[1.28,3.14]$} \\
\hline$\xi_{p}$ & {$[0,1)$} & Beta & 0.50 & {$[0.33,0.67]$} & 0.40 & {$[0.32,0.48]$} \\
\hline$\iota_{w}$ & {$[0,1)$} & Beta & 0.50 & {$[0.25,0.75]$} & 0.51 & {$[0.27,0.75]$} \\
\hline$\iota_{p}$ & {$[0,1)$} & Beta & 0.50 & {$[0.25,0.75]$} & 0.18 & {$[0.06,0.29]$} \\
\hline$\psi$ & {$[0,1)$} & Beta & 0.50 & {$[0.25,0.75]$} & 0.75 & {$[0.60,0.89]$} \\
\hline$\phi_{p}$ & $\Re^{+}$ & Normal & 1.25 & {$[1.05,1.46]$} & 1.53 & {$[1.38,1.68]$} \\
\hline$r_{\pi}$ & $\Re^{+}$ & Normal & 1.50 & {$[1.12,1.89]$} & 2.10 & {$[1.83,2.37]$} \\
\hline$\rho$ & {$[0,1)$} & Beta & 0.75 & {$[0.59,0.91]$} & 0.75 & {$[0.69,0.80]$} \\
\hline$r_{y}$ & $\Re^{+}$ & Normal & 0.12 & {$[0.04,0.21]$} & 0.17 & {$[0.09,0.24]$} \\
\hline$\pi$ & $\Re^{+}$ & Gamma & 0.60 & {$[0.43,0.76]$} & 0.61 & {$[0.49,0.74]$} \\
\hline $100\left(\beta^{-1}-1\right)$ & $\Re^{+}$ & Gamma & 0.25 & {$[0.09,0.40]$} & 0.17 & {$[0.07,0.27]$} \\
\hline$l$ & $\Re^{+}$ & Normal & 0.17 & {$[0.01,0.34]$} & 0.17 & {$[0.01,0.33]$} \\
\hline $100(\gamma-1)$ & $\Re^{+}$ & Normal & 0.55 & {$[0.39,0.71]$} & 0.35 & {$[0.29,0.41]$} \\
\hline$\alpha$ & $\Re^{+}$ & Normal & 0.30 & {$[0.22,0.38]$} & 0.21 & {$[0.17,0.26]$} \\
\hline$\rho_{z}$ & {$[0,1)$} & Beta & 0.50 & {$[0.25,0.75]$} & 0.98 & {$[0.97,0.99]$} \\
\hline$\rho_{f}$ & {$[0,1)$} & Beta & 0.50 & {$[0.25,0.75]$} & 0.90 & {$[0.85,0.96]$} \\
\hline$\rho_{g}$ & {$[0,1)$} & Beta & 0.50 & {$[0.25,0.75]$} & 0.96 & {$[0.94,0.98]$} \\
\hline$\rho_{v}$ & {$[0,1)$} & Beta & 0.50 & {$[0.25,0.75]$} & 0.37 & {$[0.15,0.57]$} \\
\hline$\rho_{m}$ & {$[0,1)$} & Beta & 0.50 & {$[0.25,0.75]$} & 0.36 & {$[0.26,0.46]$} \\
\hline$\rho_{a}$ & {$[0,1)$} & Beta & 0.50 & {$[0.25,0.75]$} & 0.86 & {$[0.78,0.95]$} \\
\hline$\rho_{b}$ & {$[0,1)$} & Beta & 0.50 & {$[0.25,0.75]$} & 0.96 & {$[0.94,0.98]$} \\
\hline$\sigma_{z 0}$ & $\Re^{+}$ & InvGamma & 0.25 & {$[0.11,0.40]$} & 0.34 & {$[0.27,0.40]$} \\
\hline$\sigma_{z 1}$ & $\Re^{+}$ & InvGamma & 0.11 & {$[0.05,0.18]$} & 0.14 & {$[0.06,0.21]$} \\
\hline$\sigma_{z 2}$ & $\Re^{+}$ & InvGamma & 0.11 & {$[0.05,0.18]$} & 0.13 & {$[0.06,0.19]$} \\
\hline$\sigma_{z 3}$ & $\Re^{+}$ & InvGamma & 0.11 & {$[0.05,0.18]$} & 0.11 & {$[0.05,0.17]$} \\
\hline$\sigma_{z 4}$ & $\Re^{+}$ & InvGamma & 0.11 & {$[0.05,0.18]$} & 0.12 & {$[0.06,0.18]$} \\
\hline$\sigma_{z 5}$ & $\Re^{+}$ & InvGamma & 0.11 & {$[0.05,0.18]$} & 0.16 & {$[0.08,0.23]$} \\
\hline$\sigma_{f}$ & $\Re^{+}$ & InvGamma & 0.25 & {$[0.11,0.40]$} & 0.23 & {$[0.13,0.34]$} \\
\hline$\sigma_{g}$ & $\Re^{+}$ & InvGamma & 0.25 & {$[0.11,0.40]$} & 0.44 & {$[0.38,0.49]$} \\
\hline$\sigma_{v}$ & $\Re^{+}$ & InvGamma & 0.25 & {$[0.11,0.40]$} & 0.41 & {$[0.28,0.54]$} \\
\hline$\sigma_{m}$ & $\Re^{+}$ & InvGamma & 0.25 & {$[0.11,0.40]$} & 0.16 & {$[0.13,0.18]$} \\
\hline$\sigma_{a}$ & $\Re^{+}$ & InvGamma & 0.25 & {$[0.11,0.40]$} & 0.13 & {$[0.10,0.15]$} \\
\hline$\sigma_{b}$ & $\Re^{+}$ & InvGamma & 0.25 & {$[0.11,0.40]$} & 0.47 & {$[0.32,0.62]$} \\
\hline
\end{tabular}


Table 2: Variance Decompositions

\begin{tabular}{ccccc}
\hline \hline Shock & Baseline & No News & Baseline & No News \\
\hline \multicolumn{4}{c}{ Consumption } & \multicolumn{2}{c}{ Inflation } \\
\hline Unanticipated technology & 15.65 & 5.52 & 7.52 & 6.87 \\
News about technology & 12.66 & - & 14.93 & - \\
Non-technology & 71.68 & 94.48 & 77.55 & 93.13 \\
\hline \multicolumn{7}{c}{ Investment } & \multicolumn{2}{c}{ Wage } \\
\hline Unanticipated technology & 4.28 & 3.15 & 6.60 & 2.63 \\
News about technology & 3.44 & - & 14.13 & - \\
Non-technology & 92.28 & 96.85 & 79.27 & 97.37 \\
\hline \multicolumn{7}{c}{ Output } & Interest rate \\
\hline Unanticipated technology & 11.70 & 6.40 & 7.26 & 3.87 \\
News about technology & 8.53 & - & 13.84 & - \\
Non-technology & 79.78 & 93.60 & 78.90 & 96.13 \\
\hline \multicolumn{7}{c}{ Hours } \\
\hline Unanticipated technology & 5.70 & 3.86 \\
News about technology & 5.58 & - & & \\
Non-technology & 88.72 & 96.14 \\
\hline
\end{tabular}




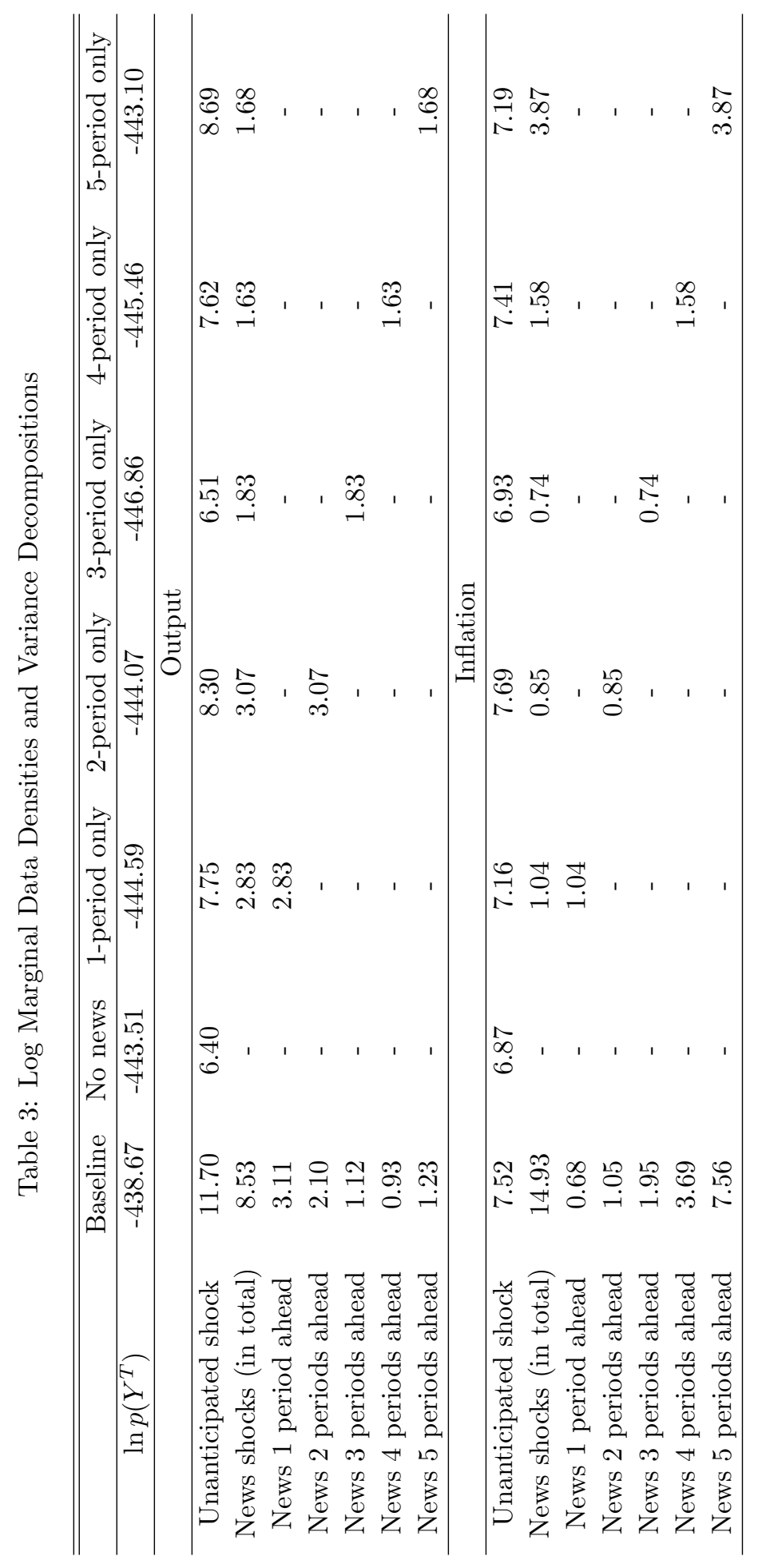




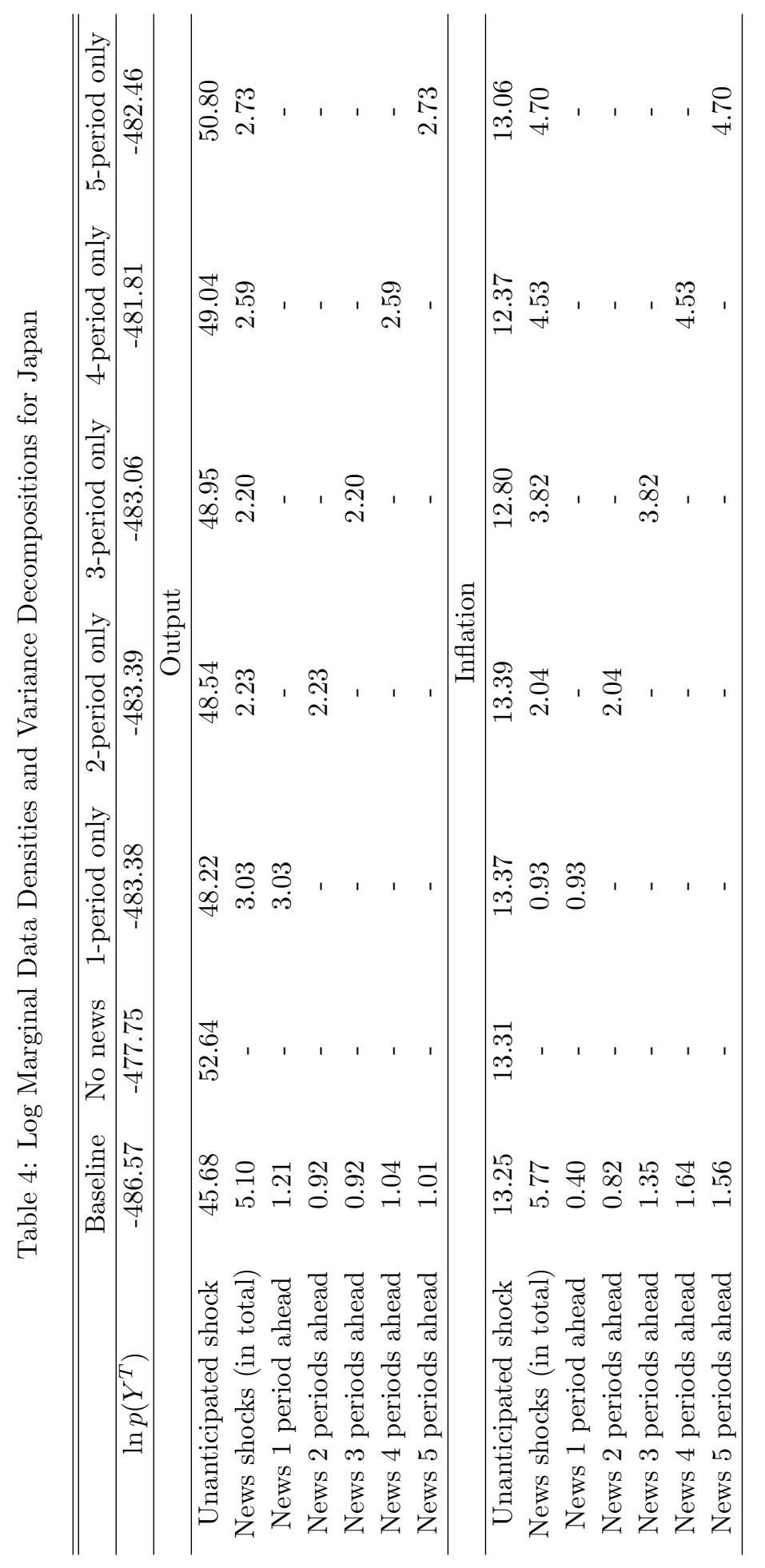


Figure 1: Impulse Responses to Productivity Shocks
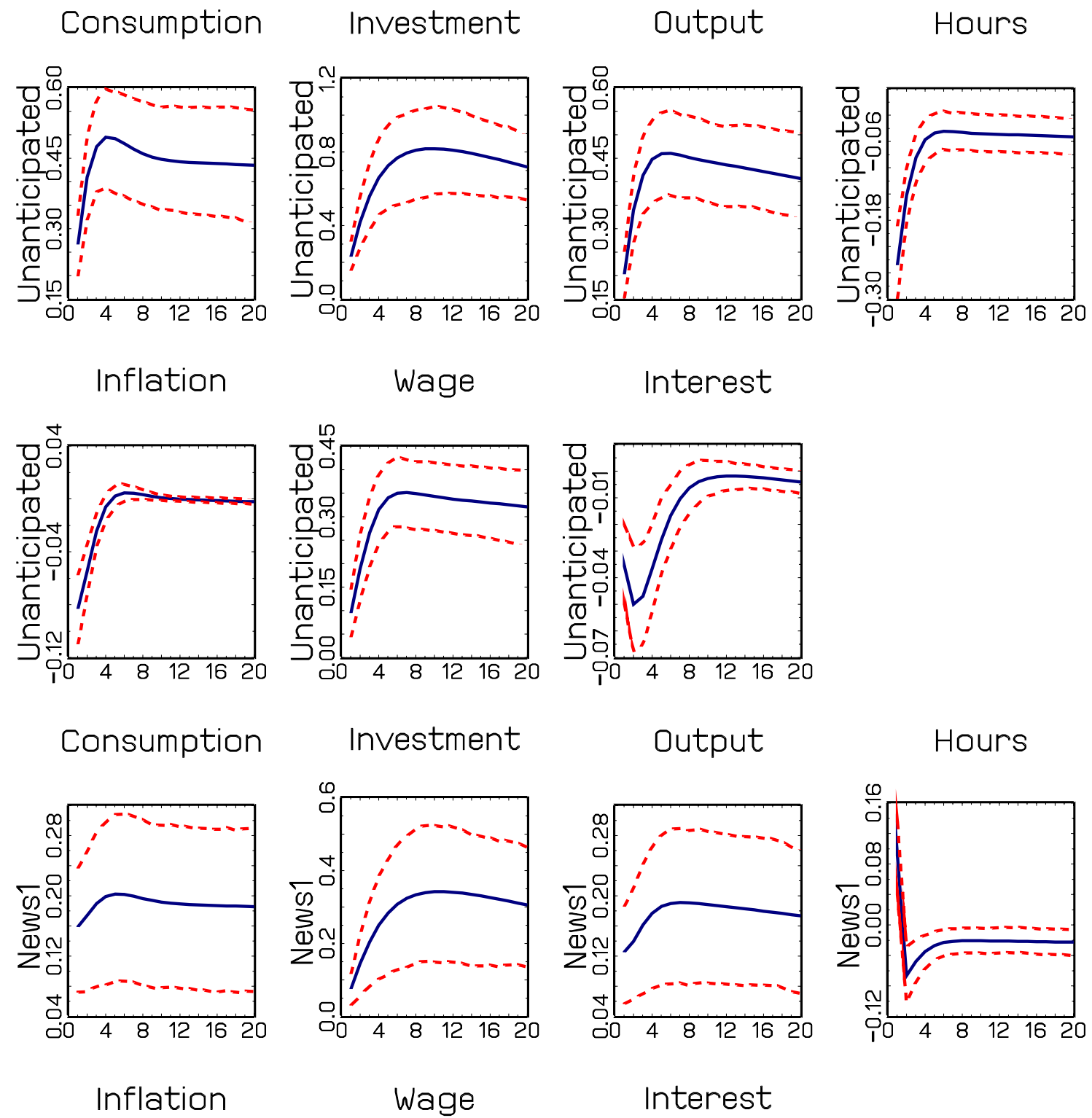

Wage
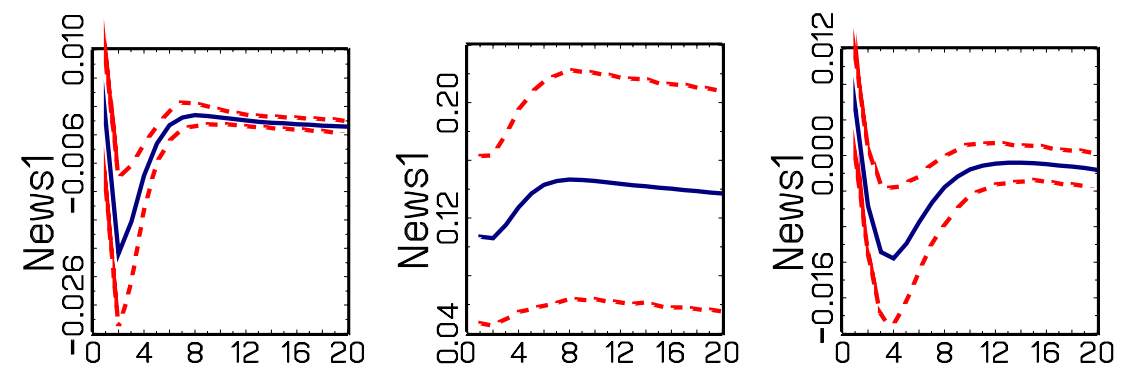

Note: The Figure depicts posterior means (solid lines) and pointwise 90\% posterior probability intervals (dashed lines) for the impulse responses to one-standard deviation shocks. 
Figure 1(continued): Impulse Responses to Productivity Shocks
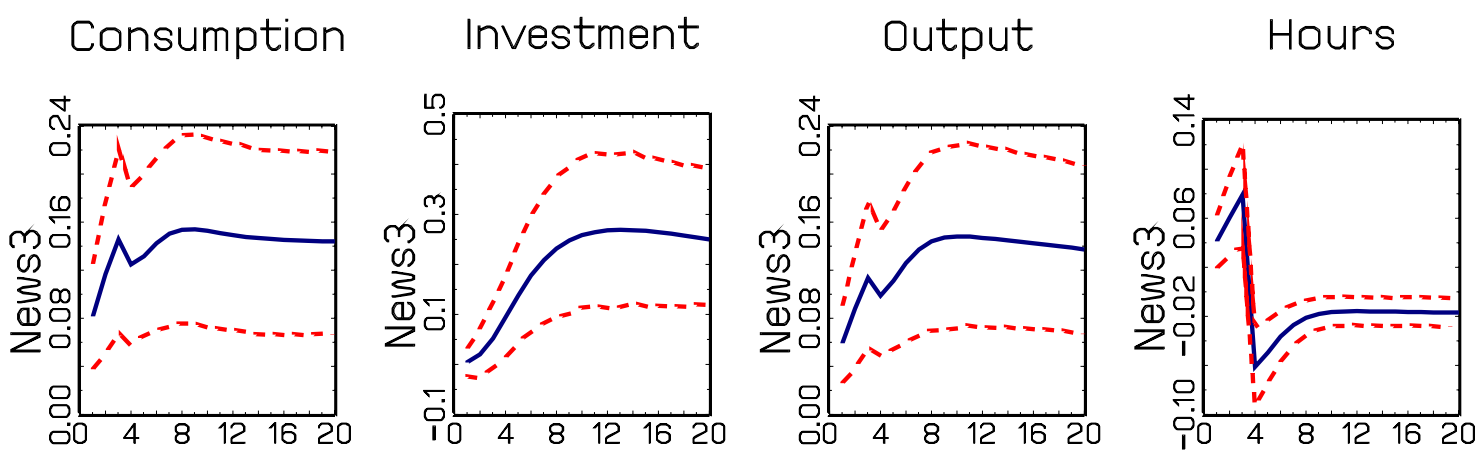

Inflation

wage

Interest
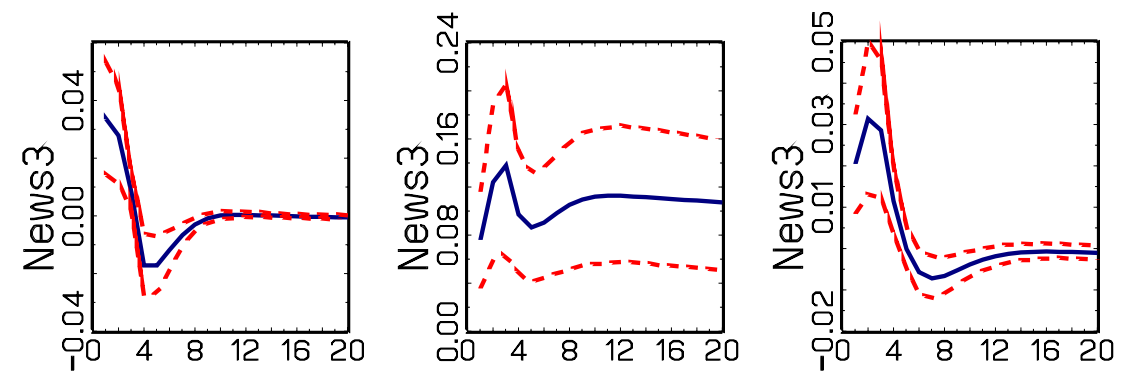

Consumption

Investment

Output

Hours
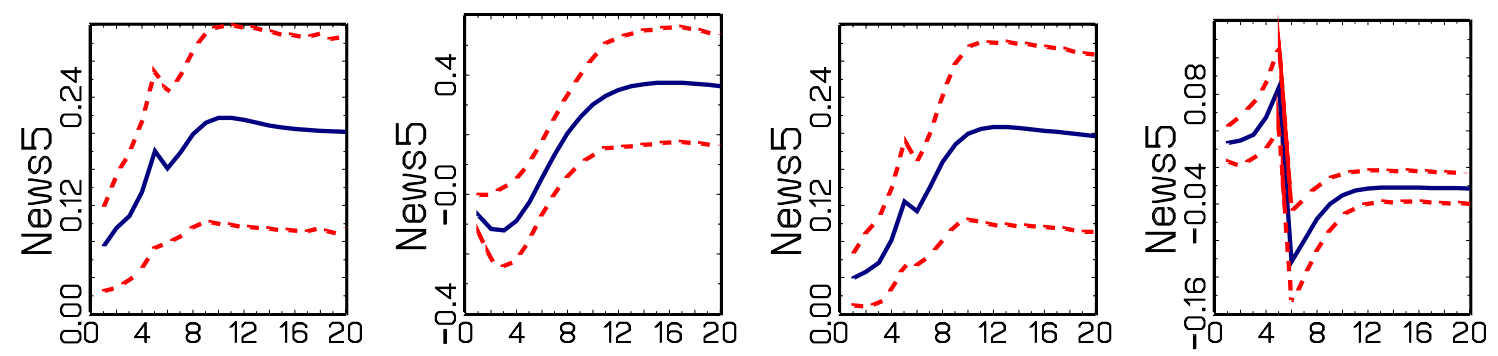

Inflation

wage

Interest
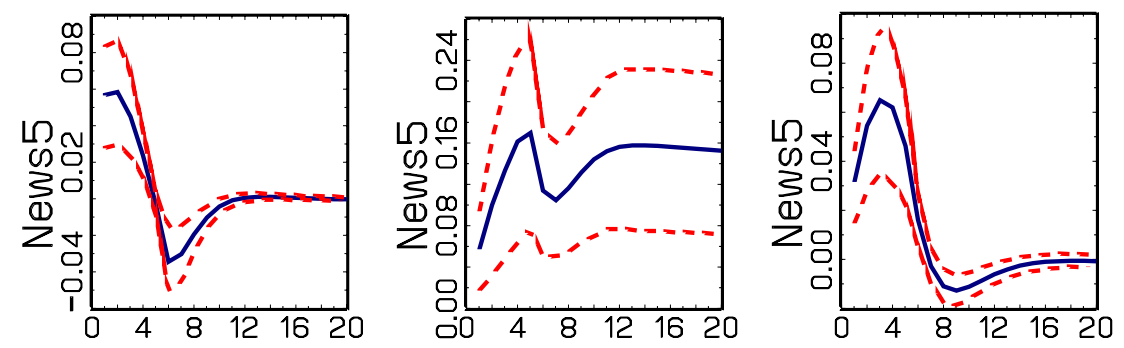

Note: The Figure depicts posterior means (solid lines) and pointwise 90\% posterior probability intervals (dashed lines) for the impulse responses to one-standard deviation shocks. 
Figure 2: Impulse Responses of Output, Hours and Productivity to Simultaneous Shocks on Unanticipated and News Components
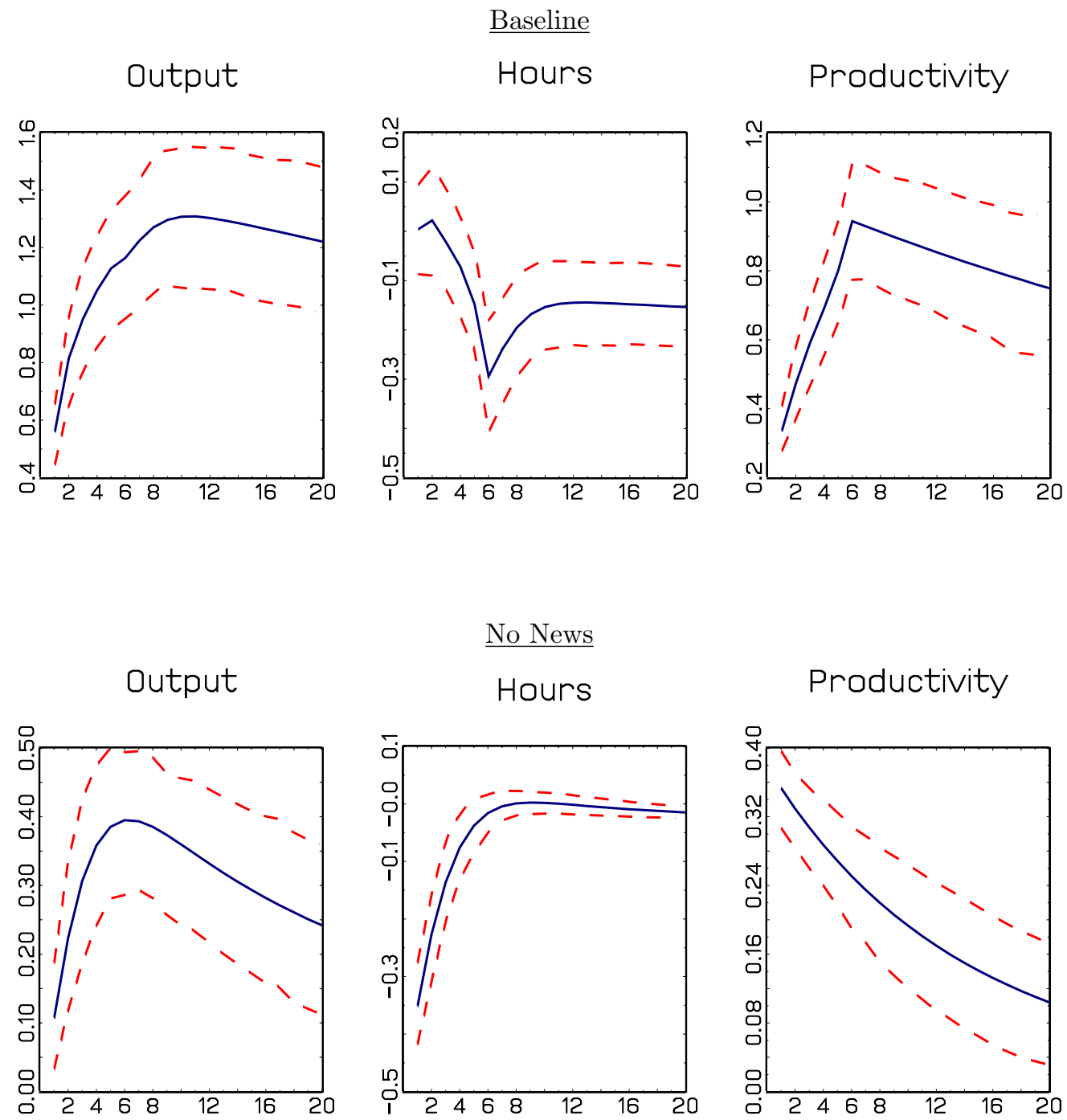

Note: The Figure depicts posterior means (solid lines) and pointwise $90 \%$ posterior probability intervals (dashed lines) for the impulse responses to one-standard deviation shocks. 